\title{
Effect of Aloe Vera Whole Leaf Extract on Fluoride Induced Pathomorphological Changes in Soft Tissues in Growing Rats
}

\section{Navathej A, Sujatha $K^{*}$ and Srilatha $C h$}

Department of Veterinary Pathology, College of Veterinary Science, Sri Venkateswara Veterinary University, Tirupati-517502, Andhra Pradesh, India.

*Corresponding author: Sujatha K, Department of Veterinary Pathology, College of Veterinary Science, Sri Venkateswara Veterinary University, Tirupati-517502, Andhra Pradesh, India, Tel: 0877-2248006; E-mail: karamalasujatha@gmail.com

Rec date: Jun 13, 2015; Acc date: Sep 26, 2015; Pub date: Sep 28, 2015

Copyright: ( 2015 Sujatha K, et al. This is an open-access article distributed under the terms of the Creative Commons Attribution License, which permits unrestricted use, distribution, and reproduction in any medium, provided the original author and source are credited.

\begin{abstract}
The present study was designed to evaluate the ameliorative effect of Aloe vera extract on fluoride induced toxic changes in soft tissues of rats. The present study was carried out by procuring 72 male Wistar albino rats that were randomly divided into four groups consisting of 18 rats in each group. Sodium Fluoride was gavaged per orally using water as vehicle @ $18 \mathrm{mg} \mathrm{NaF} / \mathrm{kg}$ body weight to groups II and Aloe Vera @ $200 \mathrm{mg} / \mathrm{kg}$ body wt. in distilled water was given along with Sodium Fluoride to group IV for 6 weeks to study ameliorative effects. Group I and III were treated with distilled water and Aloe vera respectively. Six rats from each group were sacrificed at fortnight interval. Gross changes were noticed in liver, testis, lung and spleen. Histopathologically, the liver revealed perivascular and periportal infiltration of MNCs, vesicular fatty change, periportal fibroblast proliferation, extensive bile ductular proliferation. In kidneys, atrophied and cystic glomeruli, extensive degenerative changes in tubular epithelial cells were noticed. Cerebrum revealed gliosis and demyelinating changes and in cerebellum. In testes, interstitial edema, desquamation of germinal epithelium and eosiniphillic granular debris in the lumen of the seminiferous tubules and necrotic changes were noticed. In Aloe vera ameliorated rats, these changes in different organs were less intense and by the end of experiment liver came to near normal appearance.
\end{abstract}

Keywords: Naf toxicity; Pathology; Soft tissues; Aloe vera amelioration; Albino rats

\section{Introduction}

Fluorine, the 13th most abundant element of the earth's crust occurs mainly in the form of chemical compounds such as sodium fluoride or hydrogen fluoride. These are present in minerals fluorospar, fluorapatite, topaz and cryolite. In India, fluorite and topaz are widespread and contain a high percentage of fluoride. Fluoride pollution in the environment occurs through two channels, namely natural and anthropogenic sources [1]. Fluoride is frequently encountered in minerals and in geochemical deposits and is generally released into subsoil water sources by slow natural degradation of fluorine contained rocks.

Chronic fluorosis is a global problem both in human beings and animal species $[2,3]$. The problem of excess fluoride in drinking water is of recent origin in most parts of India. Digging up of shallow aquifers for irrigation has resulted in declining levels of ground water. Fluoride is frequently encountered in minerals and in geochemical deposits and is generally released into subsoil water sources by slow natural degradation of fluorine contained rocks. Long term ingestion of high levels of fluoride results in various pathological alterations in overall organs and tissues [4]. Chronic fluoride poisoning is known to cause a variety of pathological changes in soft tissues. Structural and functional changes in muscle, liver, kidney, gastrointestinal tract, and several reproductive and endocrine organs. Since drinking water is the major source of excess fluoride, different techniques were developed for fluoride removal from water. However, most of them are unfit for clinical use because of chronic nature of the problem and associated side effects after their prolonged use. In recent years, a considerable emphasis has been focused on the importance of the naturally available botanicals that can be consumed in an individual's everyday diet because of their antioxidant and anti-inflammatory properties [5].

Aloe vera has been used worldwide both for pharmaceutical, food, and cosmetic industries due to the plethora of biological activities of some of its metabolites. Aloe vera possesses anti-inflammatory, antioxidant, antitumor, anti-arthritic, antibacterial, antiulcer, hypoglycaemic effects [6]. The active ingredients that are exactly responsible for the observed effects are yet to be identified. The present work was carried out to study the oxidative damage associated with sodium fluoride toxicity and its amelioration with Aloe vera in male wistar albino rats. Materials and Methods

\section{Animals and fluoride administration}

The present study was carried out by procuring 72 male Wistar albino rats that were randomly divided into four groups consisting of 18 rats in each group. During the experiment, the animals were kept in plastic cages ( 5 animals to each cage) in a light and darkness cycle. The rats were randomised into four groups based on their body weights, so that the mean body weight of each group was comparable. Sodium Fluoride was gavaged per orally using water as vehicle @ $18 \mathrm{mgs}$ $\mathrm{NaF} / \mathrm{kg}$ body weight to group II and Aloe Vera @ $200 \mathrm{mgs} / \mathrm{kg}$ body wt. in distilled water was given along with Sodium Fluoride to group IV for 6 weeks to study ameliorative effects. Group I and III were treated with distilled water and Aloe vera respectively. Six rats from each group were randomly sacrificed at every fortnight interval after starting the experiment i.e., 2nd, 4thand 6th weeks. The experiment was conducted for 6 weeks with protocols approved by the institutional animal ethical committee. 
Citation: Navathej A, Sujatha K, Srilatha Ch (2015) Effect of Aloe Vera Whole Leaf Extract on Fluoride Induced Pathomorphological Changes in Soft Tissues in Growing Rats. J Veterinar Sci Technol S: S13-003. doi:10.4172/2157-7579.1000S13-003

Page 2 of 6

\section{Sample collection, gross and histopathology}

A detailed postmortem examination was conducted on all the sacrificed rats in all the experimental groups. The gross lesions were recorded and representative tissue pieces from liver, kidney, brain, lungs, testis, heart and intestine were collected and preserved in $10 \%$ neutral buffered formalin for histopathological studies. Fixed tissues were processed by routine paraffin embedding technique. Sections of 5-6 microns thickness were cut and were stained with routine Haematoxylin and Eosin method (H\&E) [7].

\section{Results}

Grossly liver revealed paleness throughout the experimental period in all $\mathrm{NaF}$ treated rats and such a paleness was absent in the livers of aloe ameliorated rats. Lungs of the rats from the NaF treated groups' revealed moderate to severe congestion and emphysema throughout the experimental period. In ameliorated group, lungs showed milder changes as compared to that of $\mathrm{NaF}$ treated group. By the end of experiment, slight reduction in size of testis and paleness of kidney was noticed in $\mathrm{NaF}$ treated animals and the testes of ameliorated group remained normal in size and colour.

Histopathologically, the liver revealed focal loss of hepatocytes with MNC infiltration, mild to moderate perivascular and periportal infiltration of MNCs (Figure 1), moderate vesicular fatty change (Figure 2), individualization of hepatocytes, periportal fibroblast proliferation, loss of cord like arrangement of hepatocytes, focal areas of necrosis and extensive bile ductular proliferation in majority of the $\mathrm{NaF}$ fed animals. In aloe ameliorated rats (Group IV), these changes were less intense and by the end of 6th week, liver came to near normal appearance (Figure 3).

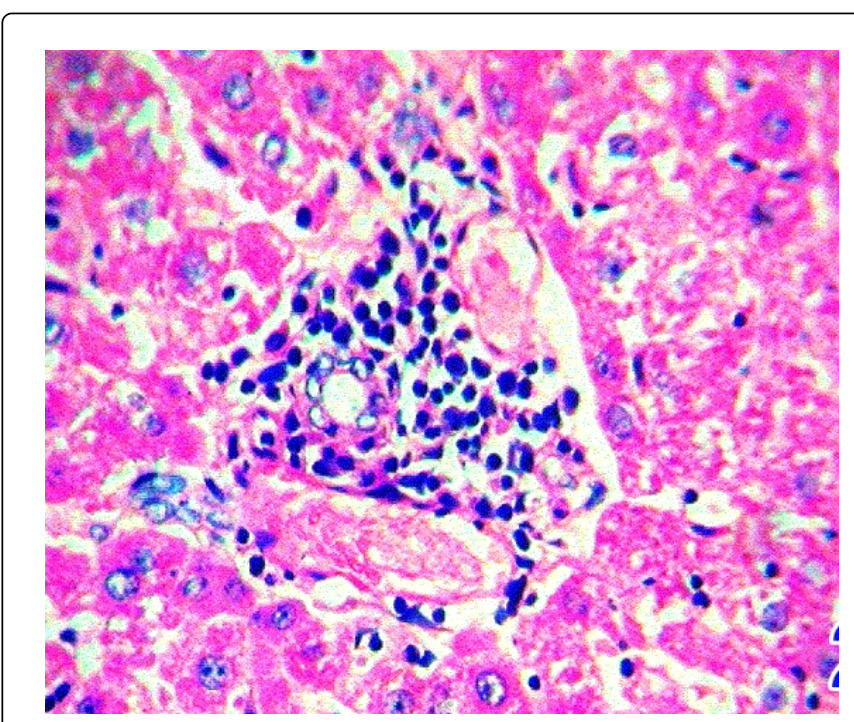

Figure 1: Liver: Group II: Section showing perivascular and periportal infiltration of MNCs and degenerated hepatocytes. $\mathrm{H}$ \& E: $\mathrm{x} 280$.

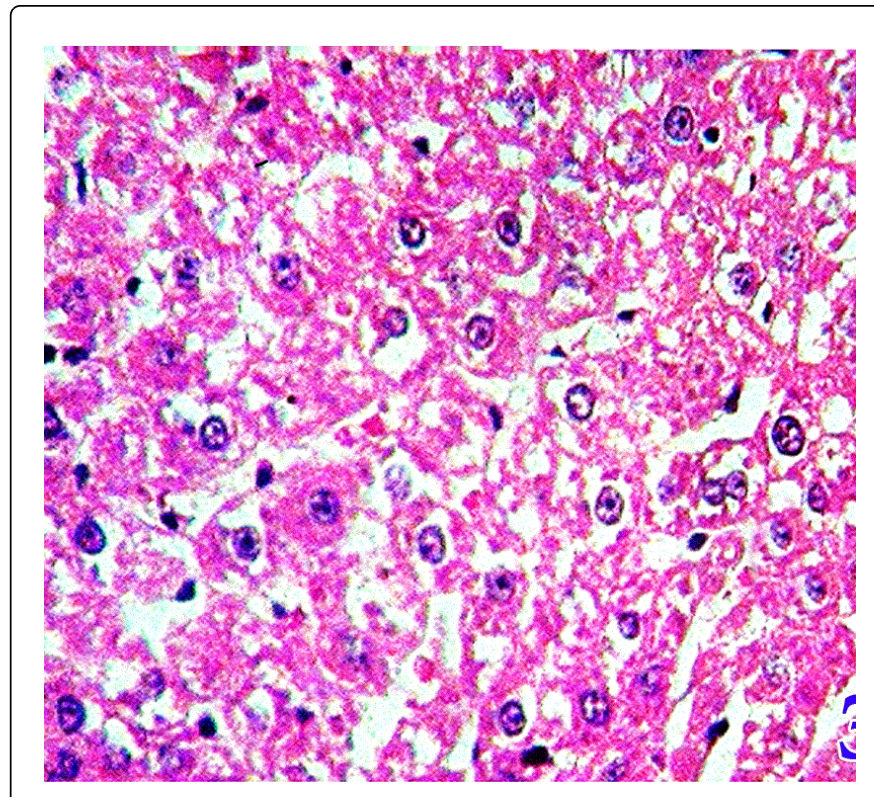

Figure 2: Liver: Group II: Section showing moderate diffuse vesicular fatty changes. $\mathrm{H} \& \mathrm{E}: \mathrm{x} 280$.

In kidneys, atrophied and cystic glomeruli (Figure 4), mild to moderate intertubular hemorrhages, extensive degenerative changes in tubular epithelial cells with cast formation in tubules, mild periglomerular and intertubular fibroblast proliferation and severe periglomerular and intertubular mononuclear cell infiltration (Figure 5) were evident in majority of $\mathrm{NaF}$ treated animals. By the end of 6th week, in aloe ameliorated rats (Group IV), these lesions were less severe to near normal appearance (Figure 6).

Lungs of group II rats revealed congestion, thickened alveolar septa with infiltration of MNCs and RBCs, focal perivascular and bronchiolar lymphoid aggregates, (Figure 7), mild to moderate emphysema and thickened blood vessels, hyperplasia of bronchial epithelium with desquamated cells in lumen (Figure 8), giant cell formation, perivascular edema, fibroblast proliferation in interstitial spaces, perivascular MNCs infiltration, peribronchial eosiniphillic infiltration and emphysema. In ameliorated group, mild congestion with focal infiltration of MNCs was observed.

Histopathologically, cerebrum revealed congestion, submeningeal haemorrhages, gliosis, central chromatolysis and demyelinating changes in $\mathrm{NaF}$ treated group. In cerebellum, sub meningeal haemorrhages, focal loss of purkinje cells in the Purkinje cell layer and congestion and haemorrhages in granular layer were observed more conspicuously in group II rats. In ameliorated group only mild changes were noticed.

In testes, congested blood vessels and interstitial edema, desquamation of germinal epithelium in S.T. and eosiniphillic granular debris in the lumen of S.T. were noticed. Majority of the seminiferous tubules revealed few spermatogonial cells at basement membrane and necrotic changes in most of the group II rats (Figure 9). In aloe ameliorated rats (Group IV), all these changes were mild.

Microscopic examination of heart revealed mild to moderate haemorrhages, sarcolytic changes (Figure 10) and mononuclear cell 
Citation: Navathej A, Sujatha K, Srilatha Ch (2015) Effect of Aloe Vera Whole Leaf Extract on Fluoride Induced Pathomorphological Changes in Soft Tissues in Growing Rats. J Veterinar Sci Technol S: S13-003. doi:10.4172/2157-7579.1000S13-003

Page 3 of 6

infiltration in between cardiac muscle fibers in most of the group II rats. All these changes were mild in aloe ameliorated rats (Group IV).

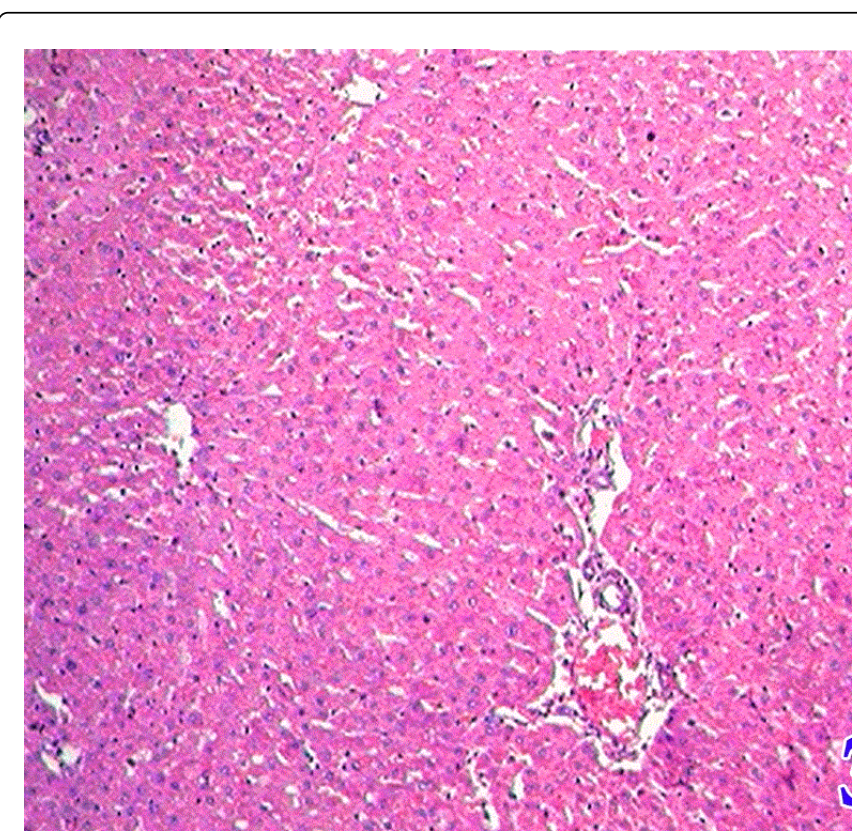

Figure 3: Liver: Group IV: Note near to normal hepatic cord arrangement. H \& E: x70.

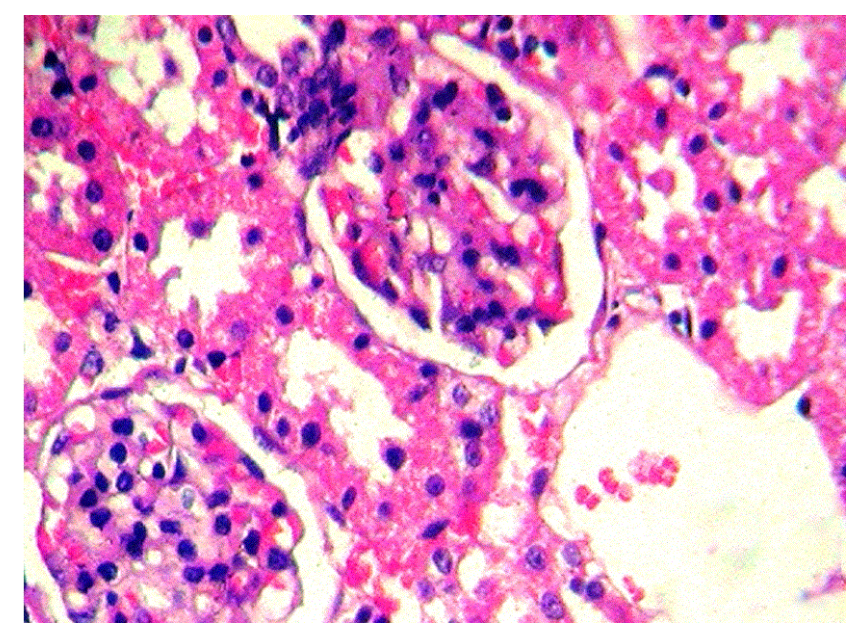

Figure 4: Kidney: Group II: Note cystic glomeruli. H \& E: x280.

Microscopically intestine of group II rats revealed increased number of goblet cells, mucosal and sub mucosal MNCs and eosiniphillic infiltration, desquamation of epithelial cells and hyperplasia of glandular epithelial cells throughout the experimental period. In ameliorated group only mild changes were noticed.

\section{Discussion}

In the present experimental study, gross changes were noticed in liver, testis, lung and spleen and histopathologically, prominent lesions in soft tissues were noticed in liver, kidney, brain followed by testis, lung and intestine of $\mathrm{NaF}$ fed groups. Fluoride is also known to cross cell membranes and to enter into soft tissues such as the kidney, brain and liver [8]. This impairment of soft tissue function is due to enhanced lipid peroxidation and decreased activities of antioxidant enzymes [9].

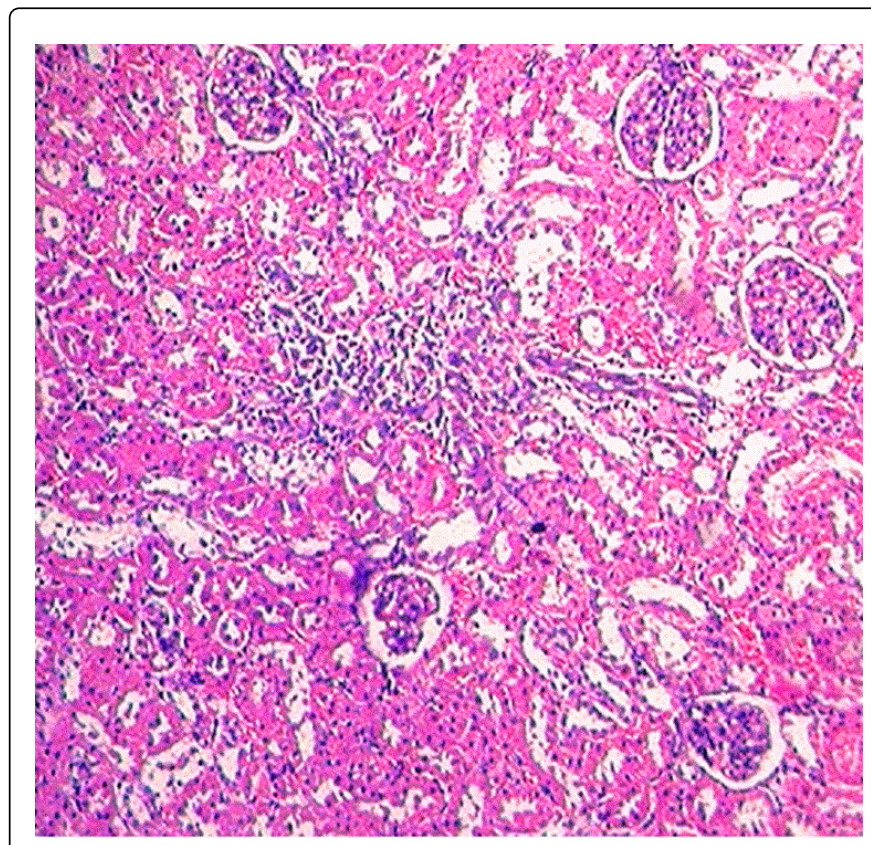

Figure 5: Kidney: Group II: Note severe intertubular mononuclear cell infiltration. $\mathrm{H} \& \mathrm{E}$ : $\mathrm{x} 70$.

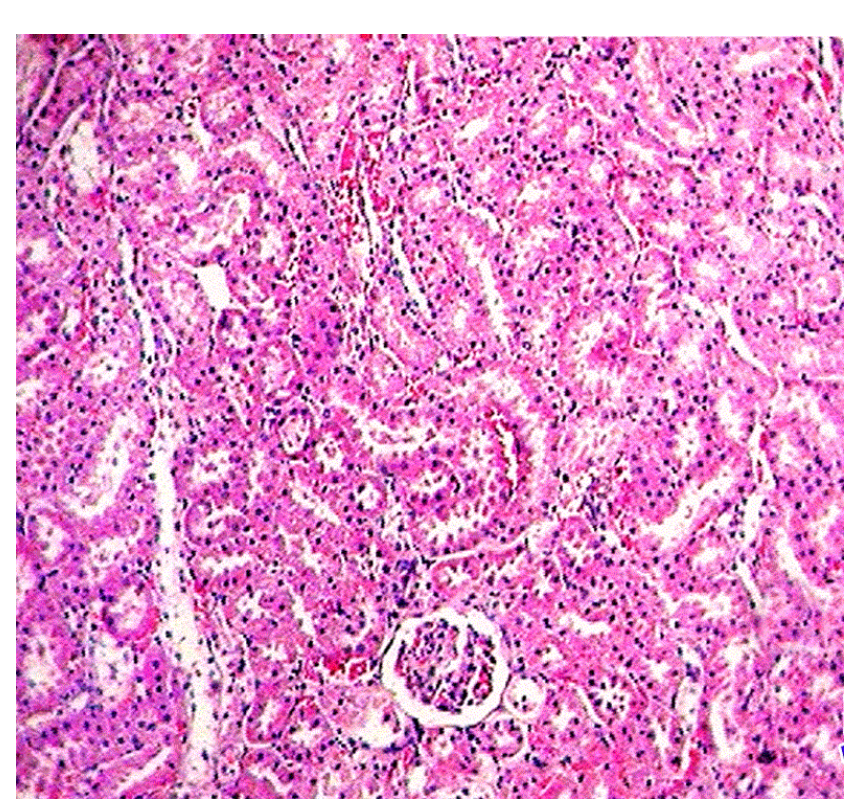

Figure 6: Kidney: Group IV: Section showing near to normal renal architecture. $\mathrm{H} \& \mathrm{E}: \mathrm{x} 70$. 
Citation: Navathej A, Sujatha K, Srilatha Ch (2015) Effect of Aloe Vera Whole Leaf Extract on Fluoride Induced Pathomorphological Changes in Soft Tissues in Growing Rats. J Veterinar Sci Technol S: S13-003. doi:10.4172/2157-7579.1000S13-003

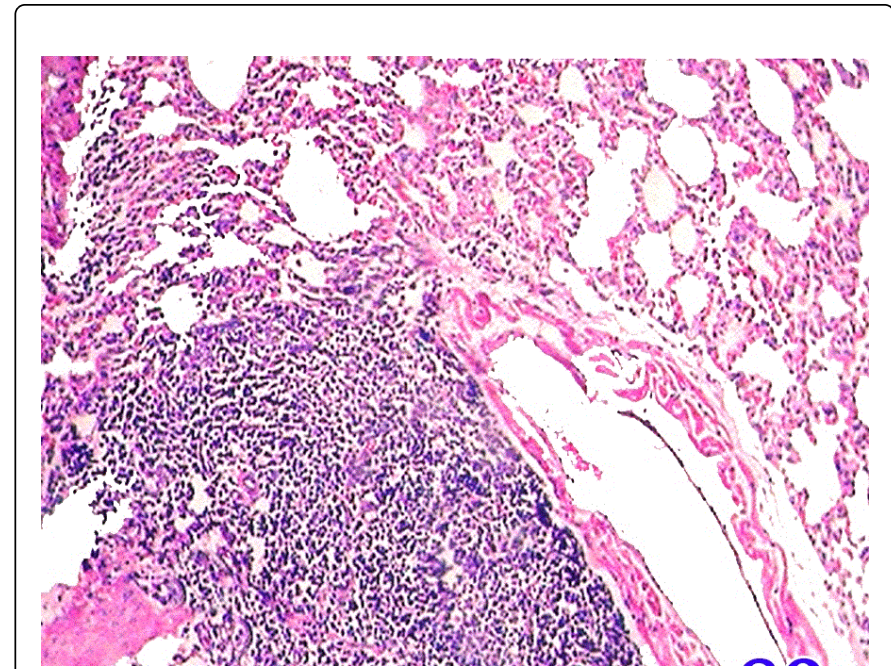

Figure 7: Lung: Group II: Section showing peribronchial MNCs infiltration.H \& E: $x 70$.

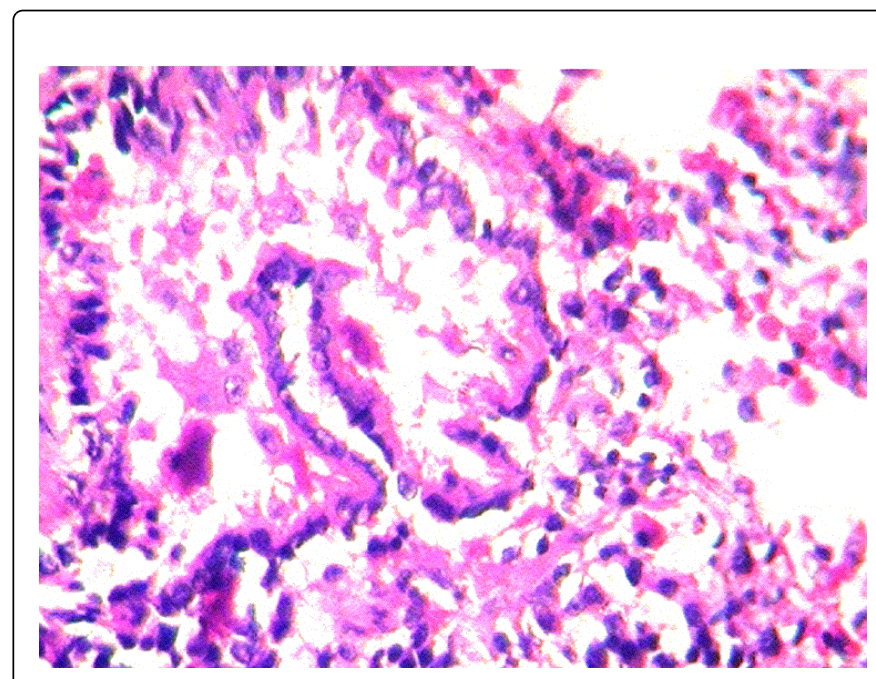

Figure 8: Lung: Group II: Brochi with desquamated cells in lumen.H \& E: x280.

Grossly, liver revealed paleness throughout the experimental period in all $\mathrm{NaF}$ treated rats and such paleness was not noticed in the livers of aloe ameliorated rats. Microscopically, liver revealed moderate sinusoidal dilatation with congestion, degenerated hepatocytes with pyknotic nuclei, focal loss of hepatocytes with MNC infiltration, mild to moderate perivascular and periportal infiltration of MNCs, anisokaryosis and karyomegaly, moderate vesicular fatty change, periportal fibroblast proliferation, lose of cord like arrangement of hepatocytes, focal areas of necrosis, extensive bile ductular proliferation in most of the NaF treated rats. These findings were in accordance with Pieta et al. [10]. These changes might be due to cytotoxic and hepatotoxic action of $\mathrm{NaF}$ on hepatocytes. The pathomorphological changes in the liver might be associated with impaired processes of oxidation-reduction [11].

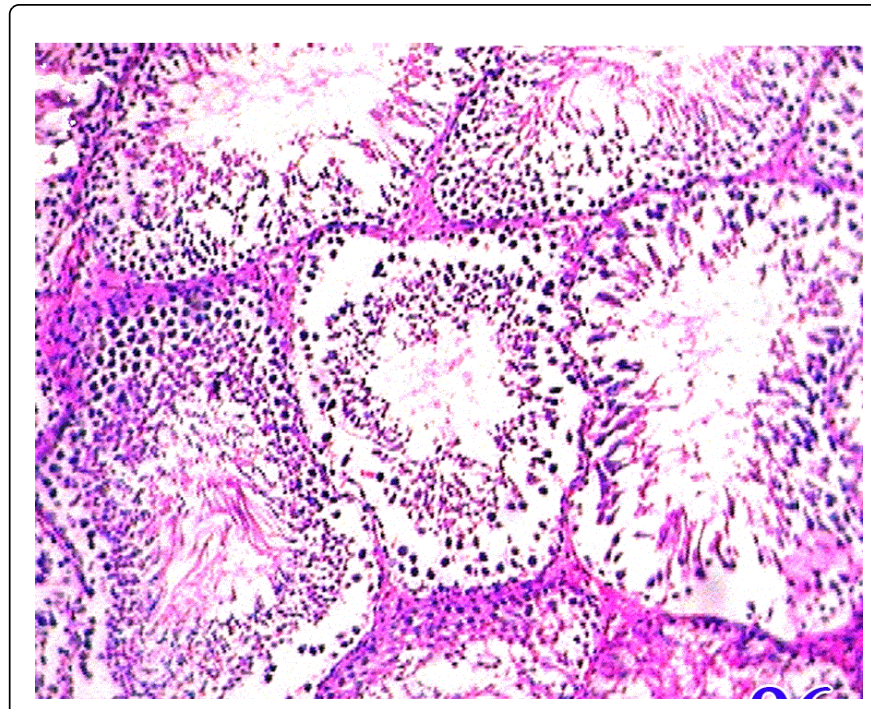

Figure 9: Testis: Group II: Note loss of germinal epithelium in S.T. and leaving few spermatogonial cells at basement membrane.H \& E: $\mathrm{x} 280$.

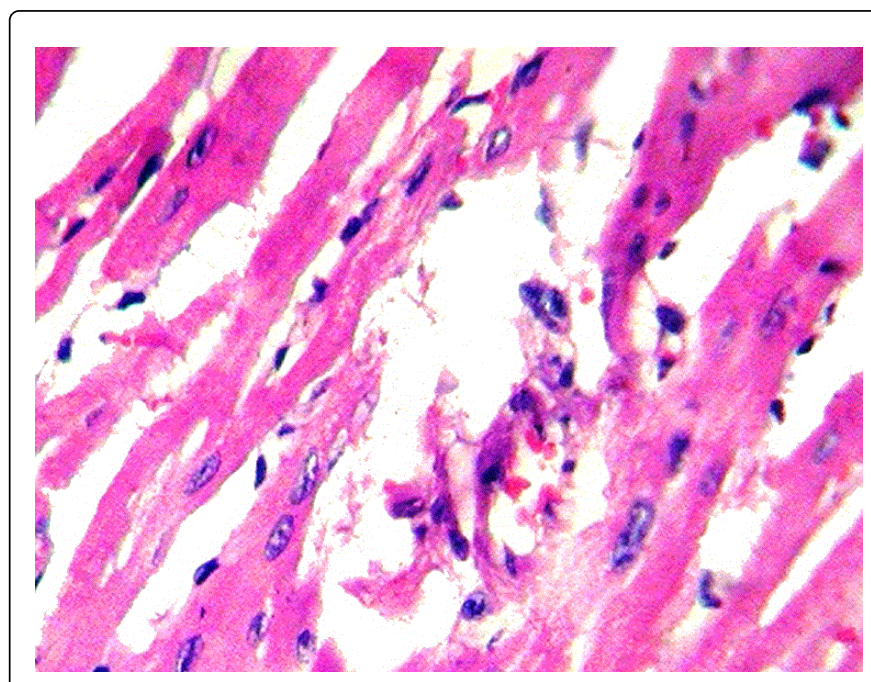

Figure 10: Heart Group II: Section showing focal sarcolytic changes. H \& E: x280.

In group IV, similar lesions but in milder form were noticed in some of the rats but liver regained it's near to normal appearance by the end of the experiment and it might be due to antioxidant activity of aloe vera and this cytoprotective effect of aloe could be attributed to its inhibition of GSH and protein SH depletions in hepatocytes [12].

Kidneys from $\mathrm{NaF}$ treated group revealed paleness grossly by the end of the experimental period. These findings were in agreement with Shashi et al. [13]. In contrary, Manocha et al. [14] and De Camargo et al. [15] did not report any gross renal change in rats and squirrel monkeys. Histopathological examination of kidney sections of rats in group II treated with fluoride revealed degeneration in renal tubular epithelial cells, congested and swollen glomerulus, mild to moderate intertubular hemorrhages, extensive degenerative changes in tubular epithelial cells with cast formation in tubules, focal intertubular 
mononuclear cell infiltration, hyperchromatic nuclei, necrosis and eosiniphillic granular debris in the tubules, atrophied and cystic glomeruli, mild periglomerular and intertubular fibroblast proliferation, cystic dilatation of tubules, thickened wall of blood vessels and severe periglomerular and intertubular mononuclear cell infiltration were evident in majority of $\mathrm{NaF}$ treated animals. Similar findings were reported by Zhan et al. [16]. These changes might be due to the harmful effects of fluoride retention and excretion of fluoride mainly from the kidney [17]. In group IV mild changes were observed and this might be due to the activation of the body's endogenous antioxidant enzyme systems following administration of aloe vera [18].

In Brain, microscopic examination of cerebral cortex of $\mathrm{NaF}$ treated rats revealed submeningeal hemorrhages, shrinkage of nerve cells with condensation of chromatin, perineuronal vacuolation in some areas, mild chromatolysis, severe demyelinating and degenerative changes giving spongiosis appearance of cerebrum, gliosis, congestion of blood vessels were noticed in majority of animals. In cerebellum, focal loss of Purkinje cells in Purkinje layer, demyelinating changes in molecular layer, shrinkage and rounding of Purkinje cells were noticed. These findings were in accordance with Shashi et al. [19]. These changes might be due to crossing of fluoride through the blood-brain barrier [20] or by interfering with neuronal energy production or free radical generation [21] or inhibiting cellular energy producing enzymes, including mitochondrial electron transport enzymes or suppression of both antioxidant enzymes and energy generating enzymes in brain. The changes noticed in the amelioration group were very mild when compared to group II. This might be due to the antioxidant and free radical scavenging properties of aloe vera [22].

In the present study, microscopically, lungs of group II rats revealed congestion, thickened alveolar septa with infiltration of MNCs and RBCs, focal perivascular and bronchiolar lymphoid aggregates, hyperplasia of bronchial epithelium with desquamated cells in lumen, widening of interstitial spaces, giant cell formation, perivascular edema, perivascular MNCs infiltration, peribronchial eosiniphillic infiltration and emphysema constantly in all animals. These lesions were in accordance with Ncu et al. [23]. These changes might be due to depleted antioxidant defense systems shifting the oxidant/antioxidant balance towards oxidative stress to mediate the toxic effects of fluoride on soft tissues [24]. In ameliorated group, similar changes were noticed like those of corresponding toxin treated groups but in a milder form that might be due to the antioxidant and anti-inflammatory properties of aloe vera [25].

In testes, congested blood vessels in interstitium and interstitial edema, thickened basement membrane of seminiferous tubules (S.T.), degenerative changes in seminiferous tubules, depletion of germinal epithelium, thickened blood vessels, desquamation of germinal epithelium in S.T. leaving few spermatogonial cells at basement membrane, shrinkage of tubules, and necrotic changes in seminiferous tubules were observed prominently. These findings were in accordance with Ravi Sekhar et al. [26]. In contrary, Sprando et al. [27] reported $\mathrm{NaF}$ treatment did not adversely affect spermatogenic activity in $\mathrm{NaF}$ treated animals. This toxic effect of fluoride on reproduction is due to inhibition of enzyme activity, particularly of enzymes whose cofactor is the cation of a bivalent metal like $\mathrm{Mg}, \mathrm{Ca}, \mathrm{Zn}$, and Se. The high affinity of fluoride toward these elements can impair enzyme activity [28]. The changes noticed in the amelioration group were very mild when compared to group II, which might be due to the radical scavenging activity of aloe vera [29].
In heart, mild MNC infiltration in between the cardiac muscle fibres, focal sarcolytic changes, mild proliferation of fibroblasts, small pockets of hemorrhages and thickened blood vessels were evident in most of the $\mathrm{NaF}$ treated rats. These changes might be due to the decreased antioxidant enzyme activity or due to membrane lipid peroxidation caused by fluoride. No reports were available in literature to compare lesions in heart due to NaF toxicity in rats. The changes noticed in the amelioration group were very mild when compared to group II which might be due to the radical scavenging activity of aloe vera [21].

In the present study sections of intestine of group II rats revealed increased number of goblet cells, mucosal and sub mucosal MNCs and eosiniphillic infiltration, desquamation of epithelial cells and hyperplasia of glandular epithelial cells throughout the experimental period. These findings were in accordance with Cigdem et al. [30]. The present lesions might be due to rapid penetration of hydrofluoric acid across the gastrointestinal cell membrance [31]. Mild changes were noticed in ameliorated group.

The present study revealed that gross pathological changes were noticed in liver, testis, lung and spleen Microscopically severe damage in soft tissues were noticed in liver, kidney, brain followed by testis, lung and intestine of $\mathrm{NaF}$ fed groups and improvement or reduced toxic intensity was observed in aloe ameliorated group. All these reduced toxic changes in different organs might be due to Aloe vera contain glycoprotein fraction that showed radical scavenging activity and isorabaichrome, an aloe derivative that has a potent antioxidant activity because of its caffeoyl group.

\section{Acknowledgments}

The authors are very much thankful to Sri Venkateswara Veterinary University, Tirupati for providing facilities to carry out Post Graduate Research in the Department of Veterinary Pathology, College of Veterinary Science, Tirupati.

\section{References}

1. Cengeloglu Y, Esengul K, Ersoz M (2002) Removal of fluoride from aqueous solution by using bauxite wastes. Sep \& Pur Tech 28: 81-86.

2. Choubisa SL (2014) Bovine calves as ideal bio-indicators for fluoridated drinking water and endemic osteo-dental fluorosis. Environ Monit Assess 186: 4493-4498.

3. Trangadia BJ, Joshi DV, Patel BJ, Kaul L, Kaul PL (2011) Spontaneous Fluorosis in Indian buffaloes. J Adv Vet Res 1: 57-60.

4. Vani M, Reddy K (2000) Effects of fluoride accumulation on some enzymes of brain and gastrocnemius muscle of mice. Fluoride 33: 17-26.

5. Nandakumar V, Singh T, Katiyar SK (2008) Multi-targeted prevention and therapy of cancer by proanthocyanidins. Cancer Lett 269: 378-387.

6. Sharrif Moghaddasi M, Sandeep Kumar Verma (2011) Aloe vera their chemicals composition and applications: A review. Int J Biol Med Res 2: 466-471.

7. Culling CFA (1974) Hand Book of Histopathological and Histochemical Techniques. Including Museum Techniques (3rdedn) p: 361.

8. Jacyszyn K, Marut A (1986) Fluoride in blood and urine in humans administered fluoride and exposed to fluoride polluted air. Fluoride 19: 26-32.

9. Guan ZZ, Yang PS, Yu ND, Zhuang ZJ (1989) An experimental study of blood biochemical diagnostic indices for chronic Fluorosis. Fluoride 22: 112-118.

10. Pieta BS, Beata Bielec, Katarzyna Birkner, Ewa Birkner (2012) The influence of vitamin $\mathrm{E}$ and methionine on the activity of enzymes and the 
Citation: Navathej A, Sujatha K, Srilatha Ch (2015) Effect of Aloe Vera Whole Leaf Extract on Fluoride Induced Pathomorphological Changes in Soft Tissues in Growing Rats. J Veterinar Sci Technol S: S13-003. doi:10.4172/2157-7579.1000S13-003

Page 6 of 6

morphological picture of liver of rats intoxicated with sodium fluoride. Food and Chemical Toxicology 50: 972-978.

11. Stawiarska-Pi $\ddot{A}^{\mathrm{m}}$ ta B, Bielec B, Birkner K, Birkner E (2012) The influence of vitamin $\mathrm{E}$ and methionine on the activity of enzymes and the morphological picture of liver of rats intoxicated with sodium fluoride. Food Chem Toxicol 50: 972-978

12. Norikura T, Kennedy DO, Nyarko AK, Kojima A, Matsui-Yuasa I (2002) Protective effect of aloe extract against the cytotoxicity of 1,4naphthoquinone in isolated rat hepatocytes involves modulations in cellular thiol levels. Pharmacol Toxicol 90: 278-284.

13. Shashi A, Singh JP, Thapar SP (2002) Toxic effects of fluoride on rabbit kidney. Fluoride 35: 38-50.

14. Manocha SL, Warner H, Olkowski ZL (1975) Cytochemical response of kidney, liver and nervous system of fluoride ions in drinking water. Histochem J 7: 343-355.

15. de Camargo AM, Merzel J (1980) Histological and histochemical appearance of livers and kidneys of rats after long-term treatment with different concentrations of sodium fluoride in drinking water. Acta Anat (Basel) 108: 288-294.

16. Zhan XA, Wang M, Xu Z-R, Li JX (2006) Toxic effects of F on kidney function and histology in young pigs. Research report Fluoride 39: 22-26.

17. Lim JK, Jansen GK, King RH (1975) Some toxicological aspects of stannous fluoride after injection as a clear, precipitate free solution compared to sodium fluoride. J Dent Res. 54: 615-24.

18. Singh RP, Dhanalakshmi S, Rao AR (2000) Chemomodulatory action of Aloe vera on the profiles of enzymes associated with carcinogen metabolism and antioxidant status regulation in mice. Phytomedicine 7: 209-219.

19. Shashi A (2003) Histopathological investigation of fluoride induced neurotoxicity in rabbits. Fluoride 36: 2 95-105.

20. Geeraerts F, Gijs G, Finne E, Crokaert R (1986) Kinetics of fluoride penetration in liver and brain. Fluoride 19: 108-12
21. Shibata T, Watanabe M, Tanaka K, Wada K, Inoue Y (1996) Dynamic changes in expression of glutamate transporter mRNAs in developing brain. Neuroreport 7: 705-709.

22. Saritha V, Anil kumar KR, Khanum F (2010) Antioxidant and antibacterial activity of Aloe vera gel extracts. Int J Pharmaceutical Bio Arch 4: 376-384.

23. Ncu, Gulle K, Karaoz E, Gultekin F, Karaoz S, et al. (2004) Biochemical and histopathological effects of chronic fluorosis on lung tissues of first generation rats. Biotechnol and Biotechnol Eq.

24. Shivarajashankara YM, Shivashankara AR, Gopalakrishna Bhat $\mathrm{P}$, Muddanna Rao S, Hanumanth Rao S (2002) Histological changes in the brain of young fluoride intoxicated rats. Fluoride 35: 12-21.

25. Sharrif Moghaddasi M, Sandeep Kumar Verma (2011) Aloe vera their chemicals composition and applications: A review. Int J Biol Med Res 2: 466-471.

26. Ravi Sekhar P, Savithri Y, Kishore S, Jayasankar A, Jayantha rao (2011) Synergistic effect of sodium fluoride and cypermethrin on the somatic index and histopathology of albinio mice testes. Fluoride 44: 103-111.

27. Sprando RL, Collins TF, Black TN, Rorie J, Ames MJ, et al. (1997) Testing the potential of sodium fluoride to affect spermatogenesis in the rat. Food Chem Toxicol 35: 881-890.

28. Hodge HC, Smith FA (1972) Fluoride in Metalic Contaminants and Human Health. New York: Academic Press p.163.

29. $\mathrm{Hu} \mathrm{Y,} \mathrm{Xu} \mathrm{J,} \mathrm{Hu} \mathrm{Q} \mathrm{(2003)} \mathrm{Evaluation} \mathrm{of} \mathrm{antioxidant} \mathrm{potential} \mathrm{of} \mathrm{aloe} \mathrm{vera}$ (Aloe barbadensis miller) extracts. J Agric Food Chem 51: 7788-7791.

30. Cigdem elbek cubukcu (2005) Effects of systemic fluoride intake on rat gastric mucosa. Ege Tip Dergisi 44: 81-85

31. Easmann RP, Steflik DE, Pashley DH, McKinney RV, Whitford GM (1984) Surface changes in rat gastric mucosa induced by sodium fluoride: a scanning electron microscopic study. J Oral Pathol 13: 255-264. 